\title{
Correction to: Rethinking natural kinds, reference and truth: towards more correspondence with reality, not less
}

\author{
Richard Boyd ${ }^{1}$ \\ Published online: 13 July 2019 \\ (c) Springer Nature B.V. 2019
}

\section{Correction to: Synthese https://doi.org/10.1007/s11229-019-02138-4}

Section 3.11 in the original publication contains a mistake. Please find here the corrected sentence.

Original publication:

By design, it won't underwrite a determinate answer to the question, 'Strictly speaking, did tritium dioxide molecules lie in the extension of 'water' as it was used in the 17th century?

It should be:

By design, it won't underwrite a determinate answer to the question, 'Strictly speaking, did di-tritium oxide molecules lie in the extension of 'water' as it was used in the 17 th century?

Publisher's Note Springer Nature remains neutral with regard to jurisdictional claims in published maps and institutional affiliations

The original article can be found online at https://doi.org/10.1007/s11229-019-02138-4.

\footnotetext{
$凶$ Richard Boyd

rnb1@cornell.edu

1 Cornell University, Ithaca, USA
} 